\title{
Right Ventricular Outflow Tract Stenting as Palliation of Critical Tetralogy of Fallot: Techniques and Results
}

\author{
Alessandra Pizzuto, Magdalena Cuman (D, Nadia Assanta, Eliana Franchi, Chiara Marrone, Vitali Pak \\ and Giuseppe Santoro *
}

check for

updates

Citation: Pizzuto, A.; Cuman, M.; Assanta, N.; Franchi, E.; Marrone, C.; Pak, V.; Santoro, G. Right Ventricular Outflow Tract Stenting as Palliation of Critical Tetralogy of Fallot:

Techniques and Results. Hearts 2021,

2, 278-287. https://doi.org/10.3390/ hearts2020022

Academic Editor:

Shakeel Ahmed Qureshi

Received: 4 March 2021

Accepted: 17 May 2021

Published: 20 May 2021

Publisher's Note: MDPI stays neutral with regard to jurisdictional claims in published maps and institutional affiliations.

Copyright: (c) 2021 by the authors. Licensee MDPI, Basel, Switzerland. This article is an open access article distributed under the terms and conditions of the Creative Commons Attribution (CC BY) license (https:/ / creativecommons.org/licenses/by/ $4.0 /)$.
Department of Paediatric Cardiology and Cardiac Surgery, Heart Hospital "G. Pasquinucci”, National Research Council-Tuscany Fondation “G. Monasterio", 54100 Massa, Italy; apizzuto@ftgm.it (A.P.); mcuman@ftgm.it (M.C.); nadia.assanta@ftgm.it (N.A.); eliana.franchi@ftgm.it (E.F.); marrone@ftgm.it (C.M.); pakv@ftgm.it (V.P.)

* Correspondence: santoropino050562@gmail.com; Tel.: +39-0585-483634

\begin{abstract}
Background. Despite current trends toward early primary repair, the surgical systemic-topulmonary shunt is still considered the first-choice palliation in patients with critical tetralogy of Fallot (TOF) and duct-dependent pulmonary circulation unsuitable for primary repair. However, stenting of the right ventricular outflow tract (RVOT) is nowadays emerging as an effective alternative to surgical palliation in selected patients. Methods and results. RVOT stenting is usually performed from a venous route, either femoral or, in selected cases, the right internal jugular vein. Less frequently, mostly in pulmonary infundibular/valvar atresia, this procedure can be performed using a hybrid surgical/interventional approach by surgical exposure of the RVOT, puncture of the atretic valve, and stent deployment under direct vision. The size and type of the most appropriate stent may be chosen, based on ultrasound measurements of the RVOT, to cover the right ventricular infundibulum completely and, at the same time, sparing the pulmonary valve, unless significant pulmonary valve annulus hypoplasia and/or supra-valvular stenosis is a significant component of the obstruction. In the large series so far published, early mortality of RVOT stenting is less than $2 \%$, comparing favourably with either Blalock-Thomas-Taussig shunt or early primary repair. In addition, morbidity and clinical sequelae of this approach do not significantly differ from surgical palliation, even if RVOT stenting shows lesser durability and a higher rate of trans-catheter re-interventions over a mid-term follow-up. Finally, similar but more balanced pulmonary artery growth than surgical palliation following RVOT stenting is reported over a mid-term follow-up. Conclusions. RVOT stenting is a technically feasible, well-tolerated, and effective palliation in critical TOF. This approach is cost-effective with respect to surgical palliation either in high-risk neonates or whenever a short-term pulmonary blood flow source is anticipated due to the early surgical repair. It effectively increases pulmonary blood flow, improves arterial saturation, and promotes balanced pulmonary artery growth over a mid-term follow-up.
\end{abstract}

Keywords: right ventricular outflow tract stenting; tetralogy of Fallot; percutaneous palliation; congenital heart diseases-duct-dependent pulmonary circulation

\section{Introduction-Historical Perspective}

Critical tetralogy of Fallot (TOF) pertains to a wide spectrum of congenital heart diseases with duct-dependent pulmonary blood flow, characterized by severe pulmonary hypoperfusion at the time of the arterial duct closure and associated with a high morbidity and mortality during the neonatal period. Primary surgical repair is the treatment of choice for most of these patients [1], allowing an effective increase of oxygen saturation and normal growth of the right ventricular outflow tract (RVOT) and pulmonary arteries. However, a small subset of patients with TOF requires early palliative intervention before complete repair due to a high surgical risk caused by poor clinical conditions and/or anatomic 
cardiac or extra-cardiac comorbidities. In these cases, primary surgical repair is associated with increased morbidity and mortality [2]. Early surgical palliation is advised in the case of neonatal comorbidities (i.e., prematurity, low birth weight, infections or extra-cardiac malformations) and complex associated cardiac lesions (i.e., complete atrio-ventricular septal defect, double outlet right ventricle arrangement, severe RVOT or pulmonary artery hypoplasia or atresia) that predict higher risk surgical repair.

Patients with critical, duct-dependent TOF due to complex malformation of the right ventricular outflow tract (RVOT) or severe valvular stenosis/hypoplasia [3] would greatly benefit from a stabilized source of pulmonary blood flow to achieve clinical improvement and growth of the pulmonary arteries, resulting in lower-risk surgical repair at a later stage [4]. Continuous intravenous infusion of prostaglandin E allows for a relatively short period of ductal patency, but in most cases, a stable and more durable pulmonary blood flow source is needed for a longer time. Historically, the first performed surgical option was direct end-to-side anastomosis with the subclavian artery-to-ipsilateral pulmonary artery (classic Blalock-Thomas-Taussig shunt) [5], later modified by the introduction of expanded poly-tetrafluoroethylene as a conduit to pulmonary artery [6], the so-called modified Blalock-Thomas-Taussig shunt (mBTT shunt). Over time, other different surgical systemic-to-pulmonary artery shunts were proposed, ranging from the descending aorta-to-left pulmonary artery (Potts procedure) [7], ascending aorta-to-right pulmonary artery (Waterston procedure) [8], and, finally, ascending aorta-to-main pulmonary artery (central shunt or Melbourne shunt) [9]. All these surgical techniques may be potentially performed without cardio-pulmonary bypass. However, in the case of hemodynamic instability after the intraoperative test of temporary pulmonary artery clamping, cardio-pulmonary bypass may be necessary, resulting in higher operative morbidity and mortality [10]. The Potts and Waterson shunt procedures significantly increase pulmonary blood flow and show high longterm durability but at the expense of high-pressure and unbalanced pulmonary blood flow, resulting in segmental pulmonary artery hypertension and uneven growth of the pulmonary vascular bed. Modified Blalock-Thomas-Taussig shunt provides better control of pulmonary blood flow, but still at the expense of its uneven distribution to the pulmonary vascular bed due to the prosthetic shunt size, length, and conduit angulations. Over a mid-term follow-up, it results in pulmonary artery distortion and left-to-right discrepancy of pulmonary artery size. Recent technical advances led to the development of the central shunt, for which the main advantage is the provision of a significant and balanced increase of the pulmonary blood flow at the same time. It results in more balanced pulmonary artery growth and longer effective palliation, although at the expense of on-cardio-pulmonary-bypass surgery. Alternatively, more complex, surgical strategies may include RVOT reconstruction with a restrictive outflow patch [11] and construction of a Sano-type right ventricular-to-pulmonary artery shunt [12], all of them needing cardiopulmonary bypass support. To date, the modified Blalock-Thomas-Taussig shunt remains the most commonly used surgical palliation, although it continues to be a relatively high-risk procedure, with an overall mortality of 7.2\% [13] despite significant technical advances in the last decades. Several types of palliative percutaneous procedures have been proposed over the years as cost-effective alternatives to surgical palliation, namely pulmonary balloon valvuloplasty, arterial duct stenting, and RVOT stenting. Pulmonary valvuloplasty was the first described percutaneous palliation of tetralogy of Fallot [14]. However, this approach did not gain widespread acceptance due to the unpredictable oxygen saturation increase and durability. A further palliative percutaneous approach was arterial duct stabilization by formalin infiltration [15,16] or stent angioplasty [17]. Arterial duct stabilization by stent implantation to achieve durable patency was consistently reported as a cost-effective palliation in critical TOF, making it possible to finely tailor the shunt magnitude to the individual patient [4,17-19]. This approach showed favourable effects compared to surgery in increasing the oxygen saturation and promoting the growth of the pul- 
monary vascular tree in different pathophysiologic settings [20], due to a significant increase and even distribution of the pulmonary blood flow [21]. In parallel with this palliation type, RVOT stenting was evaluated as a bridge towards lower-risk complete repair in this setting. The theoretical advantages of this latter approach were a more predictable anatomy of RVOT concerning the arterial duct course and the presence of a bailout arterial duct patency, resulting in lower procedural risk compared to arterial duct stabilization. An important drawback of this procedure is the need to implant the stent inside the right ventricle, with all the potential consequences due to foreign material inside a growing heart.

The first successful RVOT stenting was reported in 1997 by Gibbs et al. [22] in four patients with right ventricular outflow tract obstruction and different anatomical substrates, aged between 2 and 15 years. The procedure was successful with a mean right-to-left ventricular pressure ratio decreasing from 0.95 to 0.35 in the three patients with an intact ventricular septum and an oxygen saturation increase from $76 \%$ to $91 \%$ in the patient with TOF. Improvement was maintained at a mean follow-up of 9.7 months in three cases, but one patient required stent enlargement 17 months later due to neo-endothelial proliferation within the stent. Since this first report, several authors have described the feasibility, safety, and efficacy of RVOT stenting as an alternative to surgical palliation in TOF with duct-dependent pulmonary circulation, with some advantage on improving arterial saturation and pulmonary artery growth (Table 1). In 2009, Dohlen et al. [23] reviewed the effectiveness of RVOT stenting in nine symptomatic infants with TOF with or without pulmonary atresia, all with confluent true central pulmonary arteries, who underwent 11 RVOT stenting procedures. In their patients, stenting of the RVOT provided a safe and effective management strategy, improving arterial oxygen saturations (from a median of $73 \%$ with supplemental oxygen to a median of $94 \%$ in room air) and encouraging pulmonary artery growth. Interestingly, if there was a significant increase in arterial saturation in their initial experience, the procedure was concluded even if the entire infundibulum was not covered. However, a further strategy was to completely cover the RVOT and pulmonary valve with a single long or tandem coronary stents, since two patients developed significant cyanosis secondary to progressive muscular narrowing below the stent, which required the deployment of an additional stent. The benefit of RVOT stenting on pulmonary arterial growth was further investigated by Barron et al. [24], who assessed the effect of this procedure on subsequent surgical intervention in 32 symptomatic patients with TOF. They found a significant growth of the pulmonary arteries after RVOT stenting (the left pulmonary artery Z-score increased from -1.27 to +0.11 , while the right pulmonary artery Z-score increased from -2.02 to -0.65 ), and this could potentially improve the substrate for subsequent surgical repair. In 2013, Stumper et al. [25] reported their single centre experience of RVOT stenting in 52 consecutive patients with normally related great arteries, ventricular septal defect, and severely narrowed RVOT. They were judged to be at high risk for surgical palliation or early primary repair. The procedure resulted in a significant increase of arterial oxygen saturation (from a median of $71 \%$ to $92 \%)$ with low early mortality $(1.9 \%)$ and surgical re-intervention rate $(5.7 \%)$. The authors emphasised the importance of performing pulmonary balloon valvuloplasty at the same time as the procedure, as multilevel obstructions are typical of TOF and the importance of placing the stent across the pulmonary valve without hesitation, whenever this is deemed necessary. In 2016, Sandoval et al. [26] compared the outcome of four groups of TOF patients with confluent central pulmonary arteries, including pulmonary atresia: Stent group, primary repair (aged $<3$ months) with pulmonary stenosis, primary repair (aged $<3$ months) with pulmonary atresia, and primary repair between 3 and 11 months of age. Stent patients had the smallest pulmonary arteries and the highest number of coexisting comorbidities. Stenting allowed deferral of complete surgical repair to an age, weight, and Nakata index similar to the low-risk surgery aged $>3$ months group submitted to primary repair. The three early treatment groups had similar intensive care unit/hospital stays and high re-intervention rates in the first 12 months after repair compared with the 
surgical repair $>3$ months group. In 2017, Quant et al. [27] compared the outcome of RVOT stenting versus mBTTS by a 10-year single-centre retrospective chart review study. They included all the patients who had undergone palliation of TOF-type cardiac malformations, either by modified Blalock-Thomas-Taussig shunt $(n=41)$ or RVOT stenting $(n=60)$. They found that the RVOT stent group had a lower admission rate to the paediatric intensive care unit $(p<0.001)$ with a shorter length of stay $(p<0.003)$ and shorter cardiac ward length of stay $(p<0.001)$, while the overall mortality until the surgical repair was comparable in both groups $(p=0.698)$. The overall number of reinterventions (either surgical or catheter intervention) was higher in the RVOT stent group $(p=0.002)$. The length of palliation was significantly shorter in the RVOT stent group $(p<0.001)$, with no significant difference in cardio-pulmonary bypass time $(p=0.035)$ at repair or in the intensive care unit stay $(0.097)$ or total hospital length of stay $(p=0.029)$. Interestingly, they did not find any difference in the type of surgical repair between the two groups. The same authors compared the pulmonary arterial growth during palliation after RVOT stenting versus mBTTS in 293 patients coming forward for the complete repair of TOF-type lesions in 10 years [28]. They found that RVOT stenting promoted a better (the benefit of RVOT stenting versus mBTTS was 0.599 z-scores for the left pulmonary artery and 0.749 z-scores for the right pulmonary artery) and more constant pulmonary arterial growth, as well as better oxygen saturations compared with mBTTS in the initial palliation of Fallot-type lesions.

Finally, RVOT stenting has also been described in the case of very complex anatomic settings associated with infundibular/pulmonary valve atresia. In this case, a hybrid approach, by trans-ventricular balloon dilation and stenting of the RVOT under direct vision through medial sternotomy, appears as a safe and well-tolerated procedure $[29,30]$. Moreover, in TOF and associated atrioventricular septal defects, RVOT stenting is a safe and effective palliative option [29], promoting pulmonary arterial growth and improving oxygen saturations before surgical repair.

Table 1. The details of studies included in the review.

\begin{tabular}{ccccc}
\hline Author, Year & Procedure & Number of Patients & $\begin{array}{c}\text { Procedural Success } \\
\text { Rate }\end{array}$ & Death Rate \\
\hline Dohlen, 2009 & RVOT stenting & 9 & $9 / 9=100 \%$ & $0 / 9=0 \%$ \\
\hline Barron, 2013 & RVOT stenting & 32 & $31 / 32=97 \%$ & $1 / 32=3 \%$ \\
\hline Stumper, 2013 & RVOT stenting & 52 & $52 / 52=100 \%$ & $1 / 52=1.9 \%$ \\
\hline Sandoval, 2016 & RVOT stenting & 42 & $39 / 42=93 \%$ & $2 / 42=4.7 \%$ \\
\hline \multirow{2}{*}{ Aurigemma, 2017 [31] } & RVOT stenting & 5 & $5 / 5=100 \%$ & $0 / 5=0 \%$ \\
\hline & mBTTs/central shunt & $12 / 10$ & $20 / 22=91 \%$ & $1 / 22=4.5 \%$ \\
\hline Quandt, 2017 & RVOT stenting & 60 & $57 / 60=95 \%$ & $0 / 60=0 \%$ \\
\hline Valderrama, 2020 [32] & mBTTs & 41 & $41 / 41=100 \%$ & $2 / 41=4.9 \%$ \\
\hline
\end{tabular}

\section{Indications and Contraindications}

Even though the choice between RVOT stenting and surgical palliation strongly depends on the local policy of any single centre and the expertise of both the interventional cardiologist and the paediatric cardiac surgeon, this percutaneous approach is nowadays widely considered safer and more physiologic than the mBTT shunt. The following criteria could guide inclusion into the stenting program:

1. Patients with a high-risk profile for conventional surgical palliation: Low birth-weight neonate with or without any significant comorbidity or with unfavorable anatomic arrangement of the pulmonary arteries, such as pulmonary artery discontinuity or hypoplasia [33]. 
2. Patients at low risk for surgical palliation but with an anticipated need for short-term support to the pulmonary circulation due to the early surgical repair.

RVOT stenting might be challenging in anatomical limitations such as complex anatomy of RVOT, pulmonary infundibular/valve atresia or severe pulmonary valvular hypoplasia. A hybrid approach may be a cost-effective alternative to the pure percutaneous option [34]. Conversely, the coronary artery pattern does not seem to impact the procedural results and the outcome significantly.

\section{Technical Tips}

A cardiac ultrasound, particularly using the subcostal and parasternal short-axis view, is very useful and accurate in defining the relative contribution of the sub-valvular, valvular, and supra-valvular stenosis to the overall obstruction, as well as the anatomy of the branch pulmonary arteries, being crucial in planning and guiding this percutaneous procedure (Figure 2A,B). Indeed, the pre-procedure echocardiographic evaluation in multiple views of the length of the right ventricular infundibulum, the site of the stenoses, the size of the pulmonary valvular annulus, the morphology of the pulmonary valve, as well as the relative contribution of the main pulmonary artery trunk to the overall pulmonary hypo-perfusion are of utmost importance in choosing the type, length, and diameter of the stent to be implanted. Echocardiography may also be crucial during the stent positioning and deployment, allowing fine tailoring of the procedure in any patient.

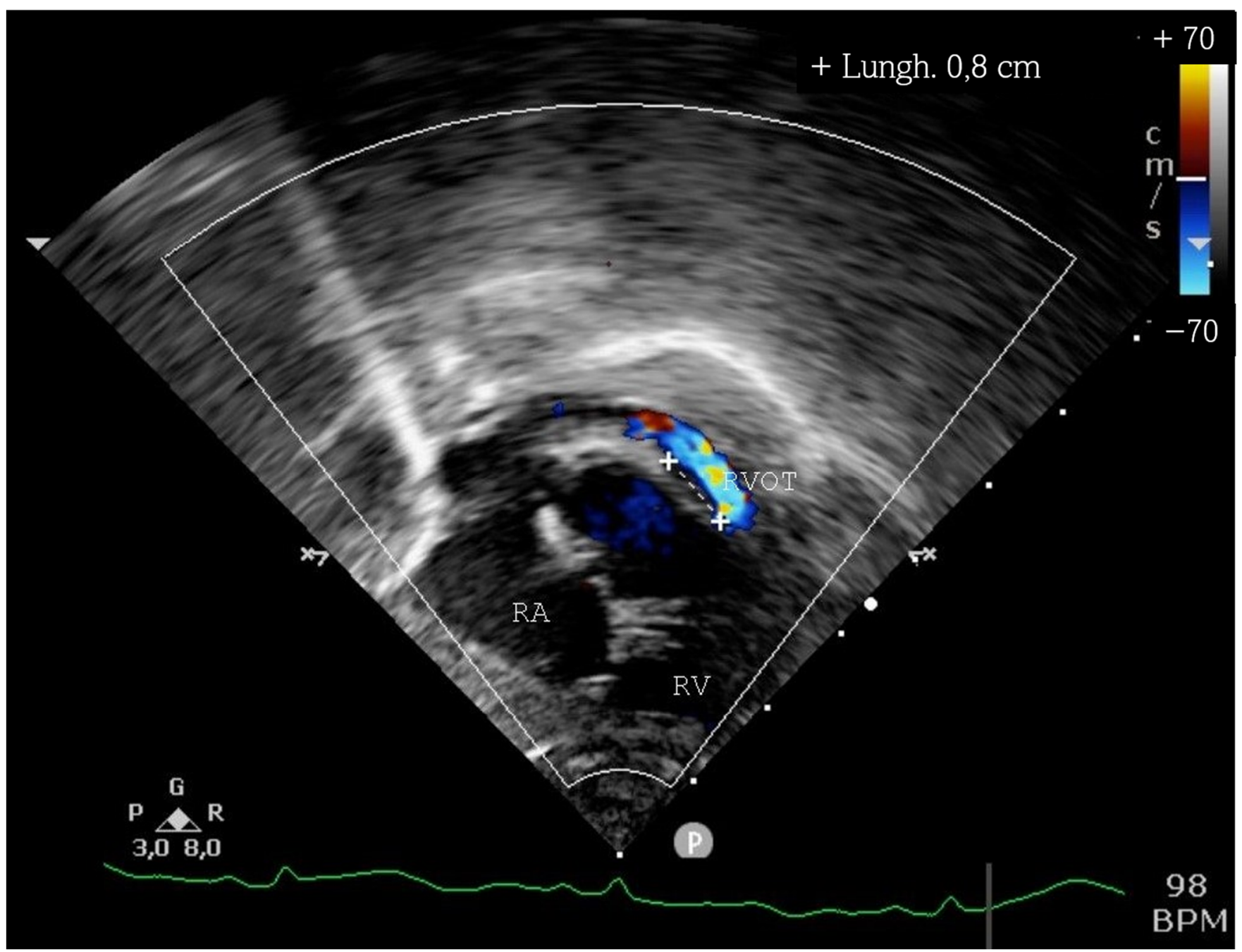

(A)

Figure 1. Cont. 


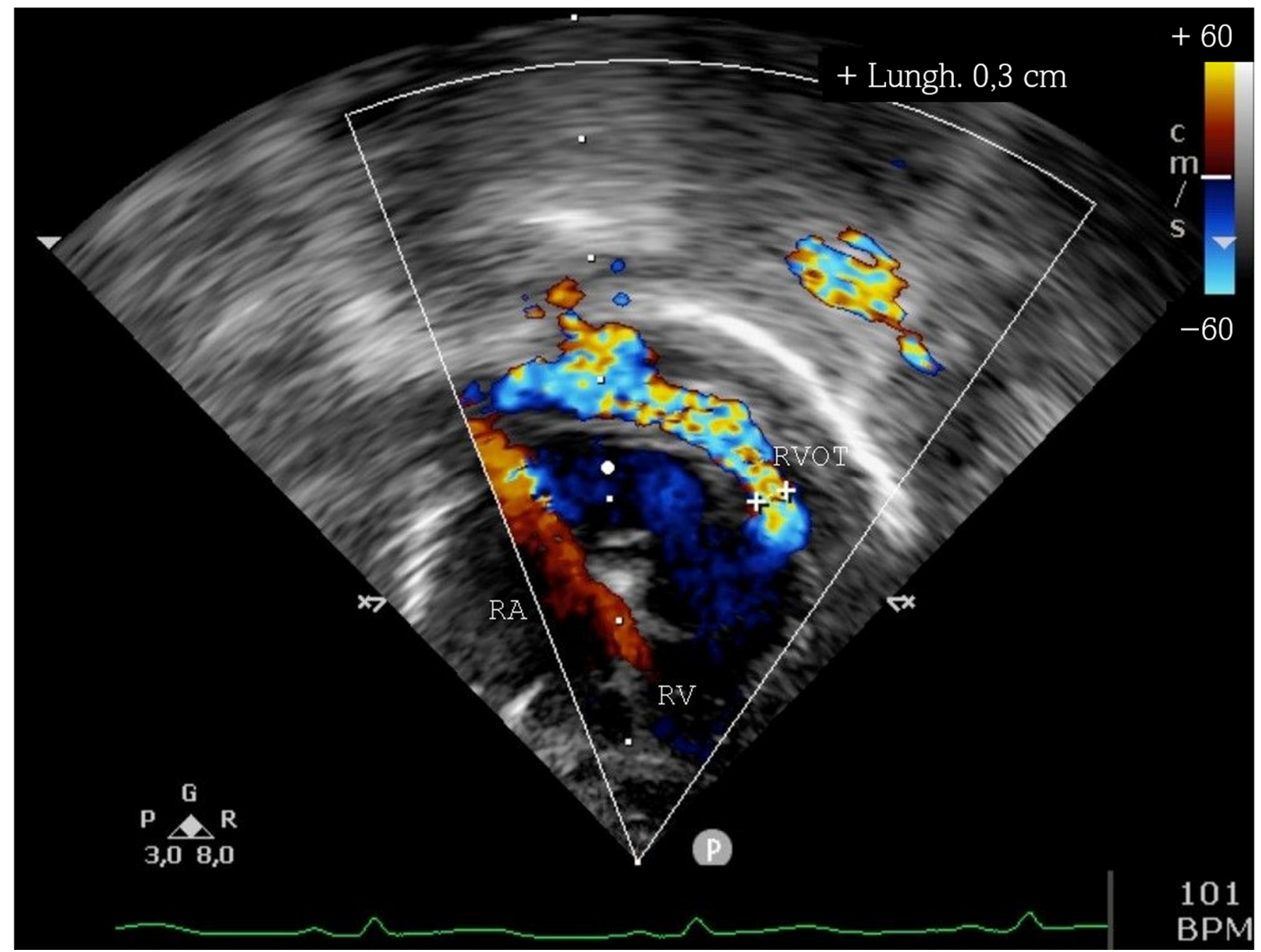

(B)

Figure 1. (A) Echocardiographic picture in subcostal right oblique view showing TOF anatomy with a long, very narrow right ventricular infundibulum. (B) Significant aliasing is imaged at the color-Doppler analysis. Abbreviations: RA = right atrium; RV = right ventricle; RVOT = right ventricular outflow tract.

The standard vascular access from the right femoral vein facilitates easily reaching of the RVOT, while the right internal jugular vein approach may be useful in low-weight neonates $(<2 \mathrm{~kg})$. A standard intravenous heparin $(100 \mathrm{IU} / \mathrm{kg})$ is given after vessel entry, and antiplatelet therapy (acetylsalicylic acid, $3-5 \mathrm{mg} / \mathrm{kg} /$ day) is recommended after stent deployment. In most cases, a 4/5 F right Judkins or Cobra catheter may allow reaching the RVOT easily. Once a correct position is achieved, baseline angiograms should be performed in a $30^{\circ}$ right anterior oblique $+20^{\circ}$ cranial and lateral views (Figure $2 \mathrm{~A}$ ). The former view usually outlines the anterior deviation of the outlet septum and the distance between the right ventricular ostium infundibulum and the pulmonary valve annulus. In contrast, the lateral view is most reliable to finely position the stent to spare the pulmonary valve or completely cover the valvular annulus and proximal pulmonary artery trunk. However, reliable measures should derive by at least two measurements in different views in order to overcome the anatomic curvature of the outflow tract and angiographic foreshortening and should be compared to the echocardiographic data. Echocardiographic measurements of the RVOT are generally the most reliable ones. Therefore, the patient should be draped to allow for peri-procedure ultrasound scanning. The stent length should be slightly longer than the longest measurement on the ultrasound, and an attempt should be made to avoid crossing the pulmonary valve unless there is significant valvular hypoplasia and/or 
supra-valvular stenosis. The type and diameter of the stent are generally chosen based on the patient weight as well as the predicted need of the palliation. In neonates weighing more than $2.5 \mathrm{~kg}$ and needing short term palliation, a $5 \mathrm{~mm}$ coronary stent is adequate, while in those who require medium-term palliation, a peripheral vascular stent, such as Formula stent (Cook Europe, Bjaeverskov, Denmark) or Valeo stent (Bard Peripheral Vascular, Tempe, AZ, USA), allows for later over-dilation. After the stent is chosen and the diagnostic catheter is inserted into the delivery sheath to enter the pulmonary arteries, the appropriate wire for the stent delivery is placed in the distal right pulmonary artery as a track for advancing the delivery sheath or guide catheter and delivering the stent. Angiographic test injections are then used to confirm the correct position of the stent before final deployment. Hand inflation of the balloon allows for fine positional adjustments of the stent during placement. Pulmonary valvuloplasty with the same balloon should be eventually performed in the case of stenotic pulmonary valve. Control angiography will then image the correct deployment of the stent and rule out any dissection or rupture (Figure 2B). It is also possible to perform direct stenting without using the delivery sheath, mainly in the case of coronary stents and/or whenever the infundibulum is not particularly tortuous. During post-procedure management, a safe approach is to start diuretic therapy in patients who experience a significant rise $(>20 \%)$ in arterial saturation to avoid potential damage resulting from increased pulmonary blood.

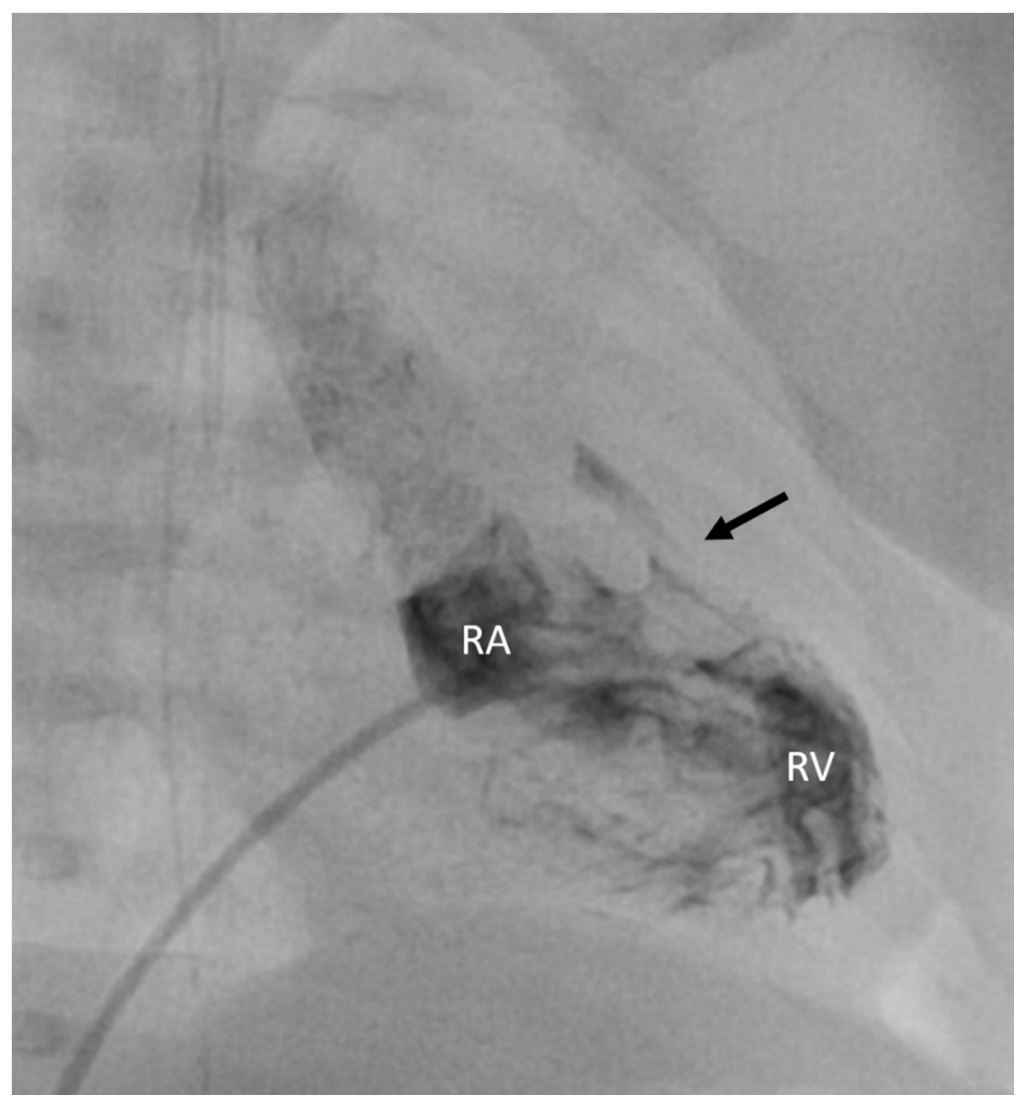

(A)

Figure 2. Cont. 


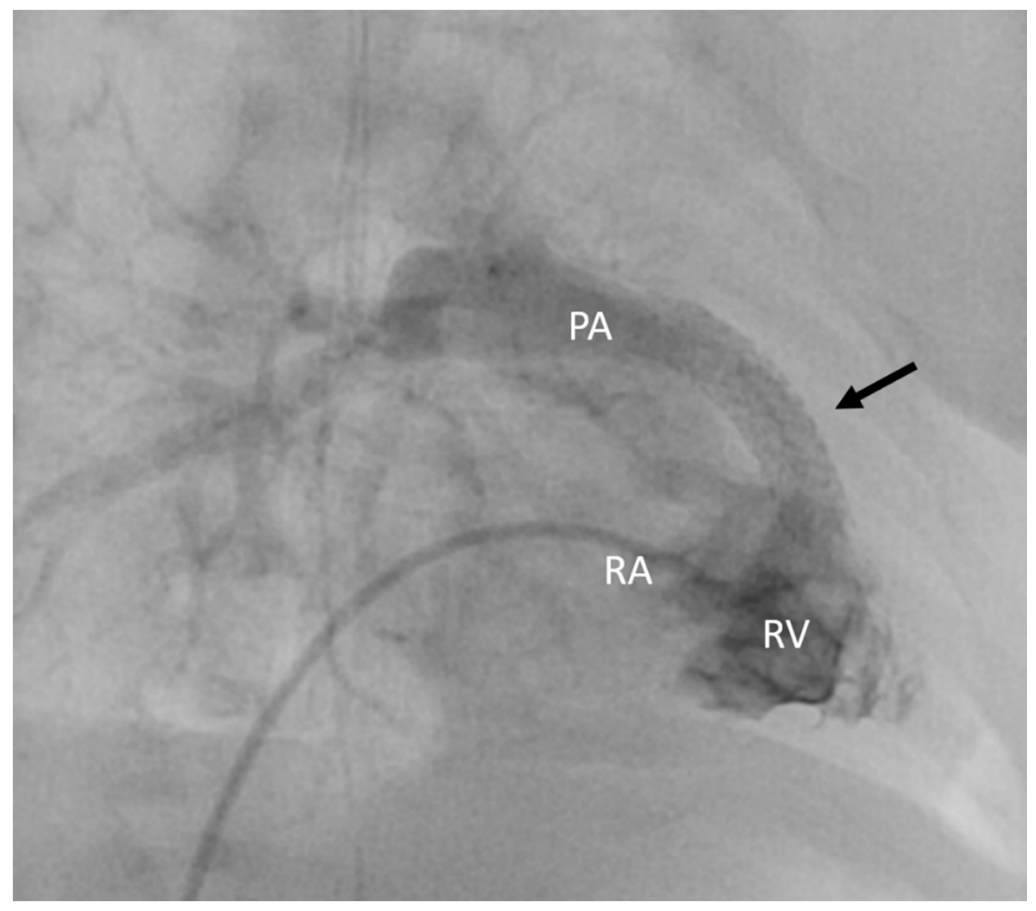

(B)

Figure 2. (A) Angiographic right anterior oblique view showing anterior deviation of the outlet septum and significant narrowing of the infundibular portion of the right ventricle. The black arrow indicates the narrow RVOT. (B) Significant increase of the pulmonary blood flow after RVOT stent angioplasty as imaged at the right anterior oblique view. The black arrow indicates the stented and enlarged RVOT. Abbreviations: RA = right atrium; RV = right ventricle; RVOT = right ventricular outflow tract; $\mathrm{PA}=$ pulmonary artery.

\section{Results}

RVOT stenting provides less durable palliation than a conventional surgical shunt [27] due to tissue reaction and fibrous tissue ingrowth, which tends to prolapse through the stent struts. The use of newer technologies, such as drug-eluting stents, could overcome this shortfall and improve the long-term patency of the stented outflow tract. Despite the lower durability than the conventional surgical shunt, stenting of the RVOT results in a greater rise of oxygen saturation and promotes better and more constant symmetrical pulmonary arterial growth than mBTT shunt palliation [28]. It is possibly due to a balanced flow to main pulmonary artery branches compared with the unfavorable graft geometry of a surgical shunt, which usually causes overgrowth of the ipsilateral pulmonary artery and lesser development of the contralateral pulmonary artery. This finding is in line with the most recent reported literature on pulmonary arterial growth following arterial duct stenting [21] or different modifications of the Norwood palliation for patients with hypoplastic left heart syndrome [35]. At the time of surgery, complete removal of the stent might not be possible in all cases, since often remnants of the stent are embedded into the myocardium. It is still unknown whether these retained stent fragments may be a focus for future ventricular arrhythmias or infections [24]. Even though removing the stent may lengthen the surgical repair, the cardio-pulmonary bypass time seems to be similar to trans-annular patch repairs of non-stented patients [24,31]. Importantly, most studies report that after the palliation period, there are no differences in the type of surgical repair [27]. This might also be due to the fact that most neonatal TOF presenting with severe cyanosis are those with more severe RVOT obstruction and smaller outflow tracts that would usually require a trans-annular patch with any surgical strategy. Finally, the overall mortality rate during palliation with RVOT stenting appears similar to that after the mBTT shunt [27]. 


\section{Limitations}

All the studies published so far are retrospective and address a relatively small cohort of patients. Moreover, in the comparative studies, patients were not randomised to either treatment, but were selected on clinical grounds and on a surgical risk assessment. Larger multicentre prospective randomized trials would be very helpful in this setting to address these limitations.

\section{Conclusions}

RVOT stenting is a technically feasible, well-tolerated, and effective palliation in critical TOF patients, at similar or lower risk than surgical palliation. It can effectively improve oxygen saturation and promote pulmonary arterial growth to lower the risk of surgical repair. It is indicated either in neonates with a high risk for surgery or in low-risk patients who need short-term pulmonary blood flow support due to the early surgical repair. RVOT stenting promotes a significant and more balanced growth of the pulmonary artery compared to the modified Blalock-Thomas-Taussig shunt. Although less durable than surgical palliation, RVOT stenting shows comparable clinical sequelae and early mortality rates. Thus, in short/medium-term palliation of critical pulmonary outflow-tract obstruction with duct-dependent pulmonary circulation, it could be proposed as a first-line approach, allowing a safer surgical repair of TOF or uni-ventricular palliation along the Fontan track in the case of more complex anatomy.

Author Contributions: A.P. and G.S. contributed equally to this work. A.P. and G.S. designed the study, contributed to discussion, wrote/reviewed/edited the manuscript. M.C., N.A., E.F., C.M., V.P. wrote the manuscript, collected, and researched the data, contributed to discussion. All authors have read and agreed to the published version of the manuscript.

Funding: This research received no external funding.

Conflicts of Interest: The authors declare no conflict of interest.

\section{References}

1. Al Habib, H.F.; Jacobs, J.P.; Mavroudis, C.; Tchervenkov, C.I.; O’Brien, S.M.; Mohammadi, S.; Jacobs, M.L. Contemporary Patterns of Management of Tetralogy of Fallot: Data From The Society of Thoracic Surgeons Database. Ann. Thorac. Surg. 2010, 90, 813-820. [CrossRef] [PubMed]

2. Van Arsdell, G.S.; Maharaj, G.S.; Tom, J.; Rao, V.K.; Coles, J.G.; Freedom, R.M.; Williams, W.G.; McCrindle, B.W. What is the Optimal Age for Repair of Tetralogy of Fallot? Circulation 2000, 102, iii-123. [CrossRef]

3. Ghaderian, M.; Ahmadi, A.; Sabri, M.R.; Behdad, S.; Dehghan, B.; Mahdavi, C.; Mansourian, M.; Shahsanaei, F. Clinical Outcome of Right Ventricular Outflow Tract Stenting Versus Blalock-Taussig Shunt in Tetralogy of Fallot: A systematic Review and Meta-Analysis. Curr. Probl. Cardiol. 2021, 46, 100643. [CrossRef]

4. Santoro, G.; Gaio, G.; Palladino, M.T.; Castaldi, B.; Iacono, C.; Esposito, R.; Capozzi, G.; Rea, A.; Russo, M.G.; Calabrò, R. Arterial duct stenting: Do we still need surgical shunt in congenital heart malformations with duct-dependent pulmonary circulation? $J$. Cardiovasc. Med. 2010, 11, 852-857. [CrossRef]

5. Blalock, A.; Taussig, H.B. The Surgical Treatment of Malformations of the Heart: In Which There Is Pulmo-Nary Stenosis or Pulmonary Atresia. J. Am. Med. Assoc. 1945, 128, 189-202. [CrossRef]

6. Donahoo, J.S.; Gardner, T.J.; Zahka, K.; Kidd, B.L. Systemic-Pulmonary Shunts in Neonates and Infants Using Microporous Expanded Polytetrafluoroethylene: Immediate and Late Results. Ann. Thorac. Surg. 1980, 30, 146-150. [CrossRef]

7. Potts, W.; Smith, S.; Gibson, S. Anastomosis of the Aorta to a Pulmonary. Certain Types in Congenital Heart Disease. JAMA 1946, 132, 627-631. [CrossRef]

8. Waterson, D.J. The Treatment of Fallot's Tetralogy in Children under One Year of Age. Rozhl. Chir. 1962, 41, 181-183.

9. Duncan, B.W.; Mee, R.B.B.; Prieto, L.R.; Rosenthal, G.L.; Mesia, C.I.; Qureshi, A.; Tucker, O.P.; Rhodes, J.F.; A Latson, L. Staged repair of tetralogy of Fallot with pulmonary atresia and major aortopulmonary collateral arteries. J. Thorac. Cardiovasc. Surg. 2003, 126, 694-702. [CrossRef]

10. Pawade, A.; Waterson, K.; Laussen, P.; Karl, T.R.; Mee, R.B. Cardiopulmonary Bypass in Neonates Weighing Less Than 2.5 kg: Analysis of the Risk Factors for Early and Late Mortality. J. Card. Surg. 1993, 8, 1-8. [CrossRef]

11. Brooks, A. Systemic-pulmonary artery shunts in infants: Modified Blalock-Taussig and central shunt procedures. Multimed. Man. Cardio-Thoracic. Surg. 2014. [CrossRef]

12. Sano, S.; Ishino, K.; Kawada, M.; Arai, S.; Kasahara, S.; Asai, T.; Masuda, Z.-I.; Takeuchi, M.; Ohtsuki, S. Right ventricle-pulmonary artery shunt in first-stage palliation of hypoplastic left heart syndrome. J. Thorac. Cardiovasc. Surg. 2003, 126, 504-509. [CrossRef] 
13. Fermanis, G.G.; Ekangaki, A.K.; Salmon, A.P.; Keeton, B.R.; Shore, D.F.; Lamb, R.K.; Monro, J.L. Twelve year experience with the modified Blalock-Taussig shunt in neonates. Eur. J. Cardio-Thoracic. Surg. 1992, 6, 586-589. [CrossRef]

14. A Qureshi, S.; Kirk, C.R.; Lamb, R.K.; Arnold, R.; Wilkinson, J.L. Balloon dilatation of the pulmonary valve in the first year of life in patients with tetralogy of Fallot: A preliminary study. Heart 1988, 60, 232-235. [CrossRef]

15. Lakier, J.; Heymann, M.; Rudolph, A. Inhibition of Closure of the Ductus Arteriosus. Pediatr. Res. 1974, 8, 351-360. [CrossRef]

16. Rudolph, A.M.; Heymann, M.A.; Fishman, N.; Lakier, J.B. Formalin Infiltration of the Ductus Arteriosus: A Method for Palliation of Infants with Selected Congenital Cardiac Lesions. N. Engl. J. Med. 1975, 292, 1263-1268. [CrossRef]

17. Gibbs, J.L.; Rothman, M.T.; Rees, M.R.; Parsons, J.M.; E Blackburn, M.; E Ruiz, C. Stenting of the arterial duct: A new approach to palliation for pulmonary atresia. Heart 1992, 67, 240-245. [CrossRef]

18. McMullan, D.M.; Permut, L.C.; Jones, T.K.; Johnston, T.A.; Rubio, A.E. Modified Blalock-Taussig shunt versus ductal stenting for palliation of cardiac lesions with inadequate pulmonary blood flow. J. Thorac. Cardiovasc. Surg. 2014, 147, 397-403. [CrossRef]

19. Bentham, J.R.; Zava, N.K.; Harrison, W.; Shauq, A.; Kalantre, A.; Derrick, G.; Chen, R.H.; Dhillon, R.; Taliotis, D.; Kang, S.-L.; et al. Duct Stenting Versus Modified Blalock-Taussig Shunt in Neonates with Duct-Dependent Pulmonary Blood Flow: Associations with Clinical Outcomes in a Multicenter National Study. Circulation 2018, 137, 581-588. [CrossRef]

20. Santoro, G.; Gaio, G.; Giugno, L.; Capogrosso, C.; Palladino, M.T.; Iacono, C.; Caianiello, G.; Russo, M.G. Ten-years, single-center experience with arterial duct stenting in duct-dependent pulmonary circulation: Early results, learning-curve changes, and mid-term outcome. Catheter. Cardiovasc. Interv. 2015, 86, 249-257. [CrossRef]

21. Santoro, G.; Capozzi, G.; Capogrosso, C.; Mahmoud, H.T.; Gaio, G.; Palladino, M.T.; Russo, M.G. Pulmonary artery growth after arterial duct stenting in completely duct-dependent pulmonary circulation. Heart 2016, 102, 459-464. [CrossRef] [PubMed]

22. Gibbs, J.L.; Uzun, O.; Blackburn, M.E.; Parsons, J.M.; Dickinson, D.F. Right ventricular outflow stent implantation: An alternative to palliative surgical relief of infundibular pulmonary stenosis. Heart 1997, 77, 176-179. [CrossRef] [PubMed]

23. Dohlen, G.; Chaturvedi, R.R.; Benson, L.N.; Ozawa, A.; Van Arsdell, G.S.; Fruitman, D.S.; Lee, K.-J. Stenting of the right ventricular outflow tract in the symptomatic infant with tetralogy of Fallot. Heart 2008, 95, 142-147. [CrossRef] [PubMed]

24. Barron, D.J.; Ramchandani, B.; Murala, J.; Stumper, O.; De Giovanni, J.V.; Jones, T.J.; Stickley, J.; Brawn, W.J. Surgery following primary right ventricular outflow tract stenting for Fallot's Tetralogy and variants: Rehabilitation of small pulmonary arteries. Eur. J. Cardio-Thoracic. Surg. 2013, 44, 656-662. [CrossRef]

25. Stumper, O.; Ramchandani, B.; Noonan, P.; Mehta, C.; Bhole, V.; Reinhardt, Z.; Dhillon, R.; A Miller, P.; De Giovanni, J.V. Stenting of the right ventricular outflow tract. Heart 2013, 99, 1603-1608. [CrossRef]

26. Sandoval, J.P.; Chaturvedi, R.R.; Benson, L.; Morgan, G.; Van Arsdell, G.; Honjo, O.; Caldarone, C.; Lee, K.-J. Right Ventricular Outflow Tract Stenting in Tetralogy of Fallot Infants With Risk Factors for Early Primary Repair. Circ. Cardiovasc. Interv. 2016, 9 , e003979. [CrossRef]

27. Quandt, D.; Ramchandani, B.; Penford, G.; Stickley, J.; Bhole, V.; Mehta, C.; Jones, T.; Barron, D.J.; Stumper, O. Right ventricular outflow tract stent versus BT shunt palliation in Tetralogy of Fallot. Heart 2017, 103, 1985-1991. [CrossRef]

28. Quandt, D.; Ramchandani, B.; Stickley, J.; Mehta, C.; Bhole, V.; Barron, D.J.; Stumper, O. Stenting of the Right Ventricular Outflow Tract Promotes Better Pulmonary Arterial Growth Compared With Modified Blalock-Taussig Shunt Palliation in Tetralogy of Fallot-Type Lesions. JACC Cardiovasc. Interv. 2017, 10, 1774-1784. [CrossRef]

29. Abumehdi, M.; Al Nasef, M.; Mehta, C.; Botha, P.; McMahon, C.; Oslizlok, P.; Walsh, K.P.; McCrossan, B.; Kenny, D.; Stümper, $\mathrm{O}$. Short to medium term outcomes of right ventricular outflow tract stenting as initial palliation for symptomatic infants with complete atrioventricular septal defect with associated tetralogy of Fallot. Catheter. Cardiovasc. Interv. 2020, 96, 1445-1453. [CrossRef]

30. Ng, L.Y.; Al-Alawi, K.; Breatnach, C.; Nolke, L.; Redmond, M.; McCrossan, B.; Oslizlok, P.; Walsh, K.P.; McGuinness, J.; Kenny, D. Hybrid Subxiphoid Perventricular Approach as an Alternative Access in Neonates and Small Children Undergoing Complex Congenital Heart Interventions. Pediatr. Cardiol. 2020, 42, 526-532. [CrossRef]

31. Aurigemma, D.; Moore, J.W.; Vaughn, G.; Moiduddin, N.; El-Said, H.G. Perforation and right ventricular outflow tract stenting: Alternative palliation for infants with pulmonary atresia/ventricular septal defect. Congenit. Heart Dis. 2018, 13, 226-231. [CrossRef]

32. Valderrama, P.; Garay, F.; Springmüller, D.; Briones, Y.; Aguirre, D.; González, R.; Becker, P.; Zamora, G.; Sánchez, L.; Castillo, G.; et al. Initial Experience in Chile with Stent Implantation in the Right Ventricle Outflow Tract in High-Risk Patients with Tetralogy of Fallot. Pediatr. Cardiol. 2020, 41, 837-842. [CrossRef] [PubMed]

33. Castleberry, C.D.; Gudausky, T.M.; Berger, S.; Tweddell, J.S.; Pelech, A.N. Stenting of the Right Ventricular Outflow Tract in the High-Risk Infant With Cyanotic Teratology of Fallot. Pediatr. Cardiol. 2013, 35, 423-430. [CrossRef] [PubMed]

34. Cools, B.; Boshoff, D.; Heying, R.; Rega, F.; Meyns, B.; Gewillig, M. Transventricular balloon dilation and stenting of the RVOT in small infants with tetralogy of fallot with pulmonary atresia. Catheter. Cardiovasc. Interv. 2013, 82, 260-265. [CrossRef] [PubMed]

35. Pruetz, J.D.; Badran, S.; Dorey, F.; Starnes, V.A.; Lewis, A.B. Differential branch pulmonary artery growth after the Norwood procedure with right ventricle-pulmonary artery conduit versus modified Blalock-Taussig shunt in hypoplastic left heart syndrome. J. Thorac. Cardiovasc. Surg. 2009, 137, 1342-1348. [CrossRef] [PubMed] 